\title{
PENGARUH RASIO LIKUIDITAS, SOLVABILITAS DAN RASIO AKTIVITAS TERHADAP PROFITABILITAS PADA PERUSAHAAN FARMASI YANG TERDAFTAR DI BURSA EFEK INDONESIA
}

\author{
*Miftahul Rohmah, Nurul Qomari, Nurul Iman \\ Fakultas Ekonomi dan Bisnis Universitas Bhayangkara Surabaya, Indonesia
}

DOI: $10.46821 /$ ekobis.v1i1.8

\begin{abstract}
ABSTRAK
Penelitian ini bertujuan untuk mengetahui pengaruh antara rasio likuiditas, solvabilitas dan aktivitas terhadap profitabilitas pada perusahaan farmasi yang terdaftar di bursa efek Indonesia. Penelitian ini merupakan penelitian kuantitatif dengan menggunakan data sekunder berupa laporan keuangan perusahaan yang terdaftar di bursa efek Indonesia periode 2013-2017. Penentuan sampel dalam penelitian ini menggunakan purposive sampling. Analis data yang digunakan uji asumsi klasik dan analisis linier berganda. Variabel independen yang digunakan dalam penelitian ini adalah likuiditas (X1), solvabilitas (X2) dan aktivitas (X3), sedangkan variabel dependen adalah profitabilitas (Y). Hasil penelitian menunjukkan bahwa ada pengaruh positif dan signifikan secara simultan dari likuiditas, solvabilitas dan aktivitas terhadap profitabilitas pada perusahaan farmasi yang terdaftar di bursa efek indonesia. Dan ada pengaruh positif dan signifikan secara parsial likuiditas, aktivitas terhadap profitabilitas, sedangkan solvabilitas berpengaruh positif yang tidak signifikan secara parsial terhadap profitabilitas pada perusahaan farmasi yang terdaftar di bursa efek Indonesia.
\end{abstract}

Kata Kunci: Likuiditas, Solvabilitas, Aktivitas dan Profitabilitas

\begin{abstract}
The purpose this research to knowing the effect liquidity ratio, solvability, and activity, on the profitability on Pharmaceutical Industry in Indonesia Stock Exchange. This research is quantitative research using financial statements on Pharmaceutical Industry in Indonesia Stock Exchange in periode 2013-2017. Stipulation of sample in this research use purposive sampling. Data analysis is multiple classic assumption test and linier regression analysis. The independent variable used in this research are Liquidity (X1), Solvability (X2), Activity (X3) and different beside the dependent variable is Profitability (Y). The results of research show that there was a positive effect and simultaneous significant of liquidity, solvability and activity on the profitability on Pharmaceutical Industry in Indonesia Stock Exchange. And there was a positive effect and partially significant of liquidity, activity on the profitability, different beside solvability has positive effect and partially significant on the profitability on Pharmaceutical Industry in Indonesia Stock Exchange.
\end{abstract}

Keywords: Liquidity, Solvability, Activity and Profitability 


\section{PENDAHULUAN}

Era globalisasi menghadirkan tantangan yang besar bagi manajemen perusahaan dan sangat erat kaitannya dengan perdagangan bebas (Free Trade). Oleh karena itu manajemen dituntut untuk mampu melakukan pengelolaan dan penyusuaian terhadap perubahan yang terjadi dalam lingkungannya agar efektif dan efisien. Perusahaan harus memiliki strategi agar dapat bertahan terhadap perubahan perubahan yang terjadi di dunia bisnis. Strategi tersebut digunakan untuk mempertahankan profitabilitas perusahaan. Besarnya profitabilitas dapat digunakan untuk menilai hasil kinerja perusahaan, karena semakin tingi tingkat profitabilitas maka semakin baik kinerja perusahaan tersebut.

Secara umum terdapat beberapa macam indikator pengukur kinerja keuangan, diantaranya yaitu rasio likuiditas, rasio solvabilitas, rasio aktivitas dan rasio profitabilitas. Rasio sendiri merupakan alat analisis yang dapat memberikan jalan keluar dan mengambarkan gejala - gejala yang tampak pada suatu laporan keuangan. Sehingga manajemen perusahaan dapat melakukan evaluasi menyeluruh terhadap kondisi keuangan dan melihat kinerja keuangan perusahaan kedepannya melalui rasio keuangan.

Perusahaan farmasi atau perusahaan obat - obatan adalah perusahaan bisnis komersial yang fokus dalam meneliti, mengembangkan dan mendistribusikan obat, terutama dalam hal kesehatan. Bila dilihat secara global, perusahaan farmasi merupakan perusahaan yang memiliki pasar yang besar. Maka, dengan demikian perusahaan farmasi harus dapat mempertahankan kesuksesan ini. Dalam mencapai kesuksesannya terdapat masalah yang akan timbul sehingga mempengaruhi dari nilai perusahaan. Oleh karena itu, penting untuk mengetahui seberapa besar faktor - faktor yang mempengaruhinya, sehingga perusahaan dapat mempersiapkan strategi untuk mengatasi masalah tersebut. Dalam menjalankan usahanya, setiap perusahaan tentunya tidak terlepas dari tujuan yang dicapai.

Hal ini juga didukung komitmen pemerintah menjadikan industri farmasi sebagai salah satu industri prioritas di Indonesia. Semakin luasnya jangkauan JKN kepada masyarakat, berarti semakin banyak masyrakat di Indonesia yang memilki akses di pelayanan kesehatan. Hal ini juga berkontribusi terhadap pertumbuhan obat dan perkembang industri farmasi secara keseluruhan dan juga dapat meringankan masyarakat dalam biaya pengobatan yang sistemnya bisa diangsur. Dan bagi perusahaan akan dapat meningkatkan profitabilitasnya.

Berdasarkan latar belakang diatas maka dapat dirumuskan latar belakang sebagai berikut: (1) Apakah rasio likuiditas, solvabilitas dan aktivitas secara simultan berpengaruh signifikan terhadap profitabilitas pada perusahaan farmasi. (2) Apakah rasio likuiditas, solvabilitas dan aktivitas secara parsial berpengaruh signifikan terhadap profitabilitas pada perusahaan farmasi. (3) Diantara rasio likuiditas, solvabilitas dan aktivitas mana yang berpengaruh dominan terhadap profitabilitas pada perusahaan farmasi.

Berdasarkan rumusan masalah diatas maka dapat dirumuskan tujuan sebagai berikut: (1) Untuk mengetahui dan menganalisa apakah rasio likuiditas, solvabilitas dan aktivitas secara simultan berpengaruh signifikan terhadap profitabilitas pada perusahaan farmasi. (2) Untuk mengatahui dan menganalisa apakah rasio likuiditas, solvabilitas dan aktivitas secara parsial berpengaruh signifikan terhadap profitabilitas pada perusahaan farmasi. (3) Untuk mengetahui 
dan menganalisa diantara rasio likuiditas, solvabilitas dan aktivitas mana yang berpengaruh dominan terhadap profitabilitas pada perusahaan farmasi.

\section{TINJAUAN PUSTAKA}

\section{Pengertian Laporan Keuangan}

Menurut Kasmir (2016:7) dalam pengertian yang sederhana, laporan keuangan adalah laporan yang menunjukan kondisi keuangan perusahaan pada saat ini atau dalam suatu periode tertentu.

\section{Rasio Keuangan}

Menurut James C Van Horne (Kasmir, 2016:104) rasio keuangan merupakan indeks yang mengubungkan dua angka akutansi dan diperoleh dengan membagi satu angka dengan angka lainnya.

\section{Rasio Likuiditas}

Menurut Fred Weston (Kasmir, 2016:129) menyebutkan bahwa rasio likuiditas merupakan rasio yang menggambarkan kemampuan perusahaan dalam memenuhi kewajiban (hutang) jangka pendek. Rasio likuiditas dalam penelitian ini dapat mengunakan beberapa alat ukur salah satunya Current Rasio. Rumus untuk mencari dapat digunakan sebagai berikut:

Current Rasio $=\frac{\text { aktiva Lancar }}{\text { Hutang Lancar }}$

\section{Rasio Solvabilitas}

Menurut Kasmir (2016:151) Rasio Solvabilitas atau leverage ratio merupakan rasio yang digunakan untuk mengukur sejauh mana aktiva perusahaan dibiayai dengan hutang. Rasio solvabilitas dalam penelitian ini dapat mengunakan beberapa alat ukur salah satunya Debt to assest ratio. Rumus untuk mencari dapat digunakan sebagai berikut:

Debt to assest ratio $=\frac{\text { Total Hutang }}{\text { Total Aset }}$

\section{Rasio Aktivitas}

Rasio Aktivitas atau activity ratio merupakan rasio yang digunakan untuk mengukur efektivitas perusahaan dalam menggunakan aktiva yang dimilikinya. (Kasmir, 2016:172). Rasio aktivitas dalam penelitian ini dapat mengunakan beberapa alat ukur salah satunya Total Assets Turn Over. Rumus untuk mencari dapat digunakan sebagai berikut:

Total Assets Turn Over $=\frac{\text { Penjualan }}{\text { total Aktiva }}$

\section{Rasio Profitabilitas}

Menurut Hery (2014:192) Rasio Profitabilitas merupakan rasio yang digunakan untuk mengukur kemampuan perusahaan dalam menghasilkan laba dari aktivitas bisnisnya. Rasio profitabilitas dalam penelitian ini dapat mengunakan beberapa alat ukur salah satunya Return on Asset. Rumus yang digunakan untuk mencari adalah sebagai berikut:

Return on Asset $=\frac{\text { Laba Bersi h }}{\text { Total Aset }}$ 


\section{METODE PENELITIAN}

Penelitian ini menjelaskan hubungan antara variabel likuiditas (X1), solvabilitas (X2) dan aktivitas (X3) terhadap profitabilitas (Y) pada perusahaan farmasi yang terdaftar di Bursa Eefek Indonesia. Penelitian ini menggunakan data sekunder yaitu dengan mengumpulkan dan mendownload data dari website resmi Bursa Eefek Indonesia yaitu www.idx.co.id. Populasi yang digunakan adalah perusahaan manufaktur sub sektor farmasi yang terdaftar di Bursa Eefek Indonesia. Sedangkan untuk sampelnya digunakan teknik purposive sampling yaitu teknik pengambilan sampel dengan kriteria tertentu sehingga didapatkan hasil sebanyak 6 perusahaan farmasi yang ada di Bursa Eefek Indonesia. Teknik analisis data yang digunakan dalam penelitian ini adalah uji asumsi klasik bertujuan untuk mengetahui dan menguji kelayakan atas model regresi yang digunakan pada penelitian ini. Dan metode analisis regresi linier berganda yang digunakan untuk mengetahui hubungan aantara variabel dependen dengan variabel independen dalam penelitian.

\section{HASIL ANALISIS DAN PEMBAHASAN Analisis Uji Asumsi Klasik \\ Uji Normalitas}

Menggunakan grafik Normal Probability Plot dapat dilihat pada gambar terlihat bahwa penyebaran data terdapat di sekitar garis diagonal memperlihatkan titiktitik yang menyebar mengikuti arah garis diagonal. Sehingga dapat disimpulakn bahwa dalam penelitian ini, uji asumsi normalitas data telah terpenuhi hingga model regresi ini layak digunakan dalam penelitian ini. Selain itu pengujian normalitas data secara analisis statistik dapat dilakukan dengan menggunakan uji Kolmogorov-smimov. Data yang berdistribusi normal ditunjukkan dengan nilai signifikasi diatas 0,05 . Hasil pengujian uji normalitas kedua variabel terlihat dalam Tabel 1.

Hasil uji normalitas dengan Berdasarkan hasil diatas pada tabel 4.5 diketahui bahwa nilai signifikan sebesar 0,983 > 0,05 yang artinya bahwa semua data dalam variabel independen dan dependen yang diuji dalam penelitian ini berdistribusi normal.

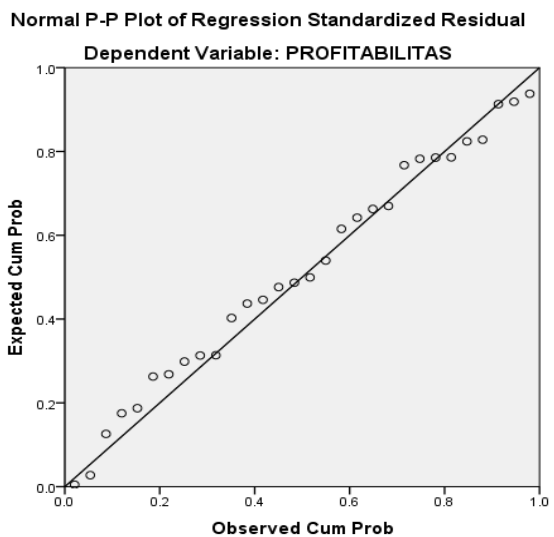

Sumber: Data Primer Diolah, 2019

Gambar 1

Normal Probability Plot 
Tabel 1

One-Sample Kolmogorov-Smirnov Test

Coefficients $^{\mathrm{a}}$

\begin{tabular}{llr}
\hline & & Unstandardized Residual \\
\hline $\mathrm{N}$ & Mean & 30 \\
Normal Parameters $^{\mathrm{a}, \mathrm{b}}$ & Std. Deviation & $0 \mathrm{E}-7$ \\
& Absolute & .04277854 \\
& Positive & .085 \\
Most Extreme Differences & Negative & .059 \\
& & -.085 \\
Kolmogorov-Smirnov Z & & .464 \\
Asymp. Sig. (2-tailed) & & .983 \\
\hline
\end{tabular}

Sumber: Data Primer Diolah, 2019

Tabel 2

Uji Multikolinieritas

\begin{tabular}{|c|c|c|c|}
\hline \multirow[t]{2}{*}{ Model } & & \multicolumn{2}{|c|}{ Collinearity Statistics } \\
\hline & & Tolerance & VIF \\
\hline \multirow{4}{*}{1} & (Constant) & & \\
\hline & LIKUIDITAS & .948 & 1.055 \\
\hline & SOLVABILITAS & 959 & 1.043 \\
\hline & AKTIVITAS & .969 & 1.032 \\
\hline
\end{tabular}

a. Dependent Variable: PROFITABILITAS

Sumber: Data Primer Diolah, 2019

\section{Uji Multikolinieritas}

Dari Tabel 2 diatas dapat dilihat bahwa variabel independen tidak ada yang memiliki nilai tolerance $>$ dari $0,10(10 \%)$. Sedangkan nilai VIF dari setiap variabel independen tidak ada yang bernilai > 10, sehingga dapat disimpulkan bahwa tidak ada multikolinieritas antara variabel dalam model regresi.

\section{Uji Heteroskedastisitas}

Dilihat dari Gambar 2 grafik scatter plot diatas menunjukkan bahwa penyebaran titik-titik secara acak yang tidak mempunyai pola yang jelas, serta penyebaran titik-titik tersebut menyebar secara merata diatas sumbu $\mathrm{X}$ maupun sumbu $\mathrm{Y}$, maka dapat disimpulkan bahwa tidak terjadi heteroskedastisitas dalam persamaan ini. Sehingga persamaan regresi layak dipakai untuk penelitian ini.

\section{Uji Autokorelasi}

Dilihat dari Tabel 3, hasil perhitungan statistik Durbin-Watson (D-W) untuk model regresi diperoleh sebesar 1,829 sedangkan tabel Durbin-Watson dengan nilai signifikan 0,5 dan jumlah sampel (n) 30 serta $K=3$ diperoleh nilai dL sebesar 1,2138 dan dU sebesar 1,6498. Karena Nilai Durbin-Watson sebesar 1,829 berada pada daerah 4-dL (4-1,2138) sebesar 2,7862 dan dU (4-1,6498) sebesar 2,3503 berdasarkan ketentuan $\mathrm{dU}<\mathrm{d}<4$-dU maka tidak terjadi autokolerasi. 


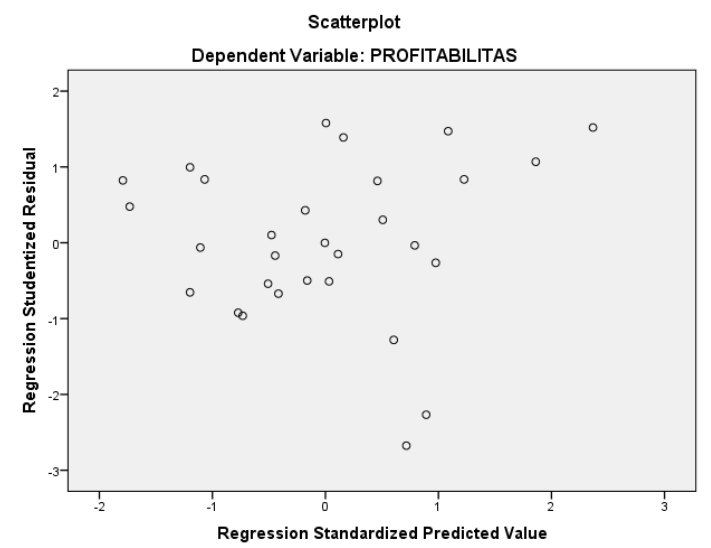

Sumber: Data Primer Diolah, 2019

Gambar 2

\section{Grafik Scatter Plot Uji Heteroskedastisitas}

Tabel 3

Model Summary ${ }^{\mathrm{b}}$

\begin{tabular}{lrrrrr}
\hline Model & R & R Square & $\begin{array}{c}\text { Adjusted R } \\
\text { Square }\end{array}$ & $\begin{array}{c}\text { Std. Error of the } \\
\text { Estimate }\end{array}$ & Durbin-Watson \\
\hline 1 & $.773^{\text {a }}$ & .597 & .551 & .04518 & 1.829 \\
\hline
\end{tabular}

Sumber: Data Primer Diolah, 2019

\section{Uji Hipotesis}

\section{Uji Simultan (Uji F)}

Berdasarkan dari Tabel 4, dapat diketahui bahwa nilai signifikan $\mathrm{F}$ sebesar 0,000 lebih kecil dari 0,05. Sehingga dapat disimpulkan bahwa variabel independen Likuiditas, Solvabilitas dan Aktivitas secara simultan atau bersama-sama berpengaruh signifikan terhadap Profitabilitas.

\section{Uji Parsial (Uji t)}

Berdasarkan Tabel 5, hasil pengujian dengan menggunakan uji t diperoleh hasil sebagai berikut:

a. Variabel likuiditas memiliki ttabel sebesar 2,056 sedangkan thitung sebesar 5,681 sehingga thitung $>$ ttabel, dengan nilai signifikan $0,00<0,05$. Sehingga dapat disimpulkan bahwa Likuiditas secara parisal mempunyai pengaruh positif yang signifikan terhadap profitabilitas.

b. Variabel solvabilitas memilikit_hitung sebesar 1,481 sedangkan t_tabel sebesar 2,056 sehinggat_hitung <t_tabel, dengan nilai signifikan $0,151<0,05$ sehingga dapat disimpulkan bahwa Solvabilitassecara parisal mempunyai pengaruh positif yang tidak signifikan terhadap profitabilitas.

c. Variabel aktivitasmemilikit_hitung sebesar 3,329 sedangkan t_tabel sebesar 2,056 sehinggat_hitung>t_tabel, dengan nilai signifikan $0,003<0,05$ sehingga dapat disimpulkan bahwa Aktivitas secara parisal mempunyai pengaruh positif yang signifikan terhadap profitabilitas. 


\begin{tabular}{llrrrrr}
\hline \multicolumn{7}{c}{ Tabel 4 } \\
Uji Simultan \\
\hline Model & Sum of Squares & \multicolumn{1}{c}{ Df } & Mean Square & F & Sig. \\
\hline 1 & Regression &, 079 & 3 &, 026 & 12,840 &, $000^{\mathrm{b}}$ \\
& Residual &, 053 & 26 &, 002 & & \\
& Total &, 132 & 29 & & & \\
\hline
\end{tabular}

a. Dependent Variable: PROFITABILITAS

b. Predictors: (Constant), AKTIVITAS, SOLVABILITAS, LIKUIDITAS

Sumber: Data Primer Diolah, 2019

Tabel 5

Uji Parsial (Uji t)

\begin{tabular}{|c|c|c|c|c|c|c|}
\hline \multirow{2}{*}{\multicolumn{2}{|c|}{ Model }} & \multicolumn{2}{|c|}{$\begin{array}{l}\text { Unstandardized } \\
\text { Coefficients }\end{array}$} & $\begin{array}{l}\text { Standardized } \\
\text { Coefficients }\end{array}$ & \multirow[b]{2}{*}{$\mathrm{T}$} & \multirow[b]{2}{*}{ Sig. } \\
\hline & & $\mathrm{B}$ & Std. Error & Beta & & \\
\hline \multirow[t]{4}{*}{1} & (Constant) &,- 230 & ,065 & & $-3,523$ &, 002 \\
\hline & LIKUIDITAS & ,049 & ,009 & ,726 & 5,681 & 000 \\
\hline & SOLVABILITAS & ,067 & ,045 & ,188 & 1,481 & ,151 \\
\hline & AKTIVITAS & ,130 & ,039 & ,421 & 3,329 & 003 \\
\hline
\end{tabular}

a. Dependent Variable: PROFITABILITAS

Perhitungan:

$\mathrm{t}_{\text {tabel }}=\mathrm{t}(\alpha / 2 ; \mathrm{n}-\mathrm{k}-1)$

$\mathrm{t}_{\text {tabel }}=\mathrm{t}(0,05 / 2 ; 30-3-1)=(0,025 ; 26)=2,056$

Sumber: Data Primer Diolah, 2019

Tabel 6

Koefisien Determinasi

Model Summary

\begin{tabular}{lrrrr}
\hline Model & $\mathrm{R}$ & $\mathrm{R}$ Square & Adjusted R Square & \multicolumn{2}{c}{$\begin{array}{c}\text { Std. Error of the } \\
\text { Estimate }\end{array}$} \\
\hline 1 &, $773^{\mathrm{a}}$ &, 597 &, 551 &, 04518 \\
\hline
\end{tabular}

a. Predictors: (Constant), AKTIVITAS, SOLVABILITAS, LIKUIDITAS

Sumber: Data Primer Diolah, 2019

\section{Pengukuran Variabel Dominan}

Dari tabel coeffisients, bahwa variabel yang dominan terhadap profitabilitas adalah likuiditas, karena likuiditas merupakan variabel yang memiliki beta tertinggi diantara variabel independen lainnya yaitu sebesar 0.726 dengan nilai signifikan $0,000<0,05$.

\section{Koefisien Determinasi}

Dari penelitian ini digunakan nilai $\mathrm{R}$ square karena apabila ada penambahan variabel independen, maka nilai $\mathrm{R}$ square dapat naik atau turun. Pada model regresi linier berganda dalam penelitian ini memiliki nilai $\mathrm{R}$ square sebesar 59,7\% yang artinya bahwa variasi atau variabel dependen (Rasio Profitabilitas) dapat dijelaskan oleh variabel independen yaitu rasio likuiditas, solvabilitas dan aktivitas sebesar 59,7\% sedangkan sisanya 40,3\% dipengaruhi oleh variabel lainnya (Tabel 6).

\section{SIMPULAN}

Berdasarkan hasil penelitian dari persamaan regresi linier berganda mengenai pengaruh variabel independen terhadap variabel dependen dapat disimpulkan sebagai berikut: 1) Variabel likuiditas, solvabilitas dan aktivitas secara simultan berpengaruh positif dan signifikan terhadap profitabilitas. 2) Variabel likuiditas secara parsial berpengaruh 
signifikan terhadap variabel dependen profitabilitas. Variabel solvabilitas secara parsial berpengaruh tidak signifikan terhadap variabel dependen profitabilitas. Semakin tinggi solvabilitas maka tidak memiliki pengaruh terhadap profitabilitas. Variabel aktivitas secara parsial berpengaruh signifikan terhadap variabel dependen profitabilitas. Semakin tinggi perputaran modal maka akan berpengaruh terhadap profitabilitas. 3) Variabel likuiditas merupakan variabel yang dominan. Hal ini dibuktikan dengan nilai koefisien beta mempunyai nilai tertinggi dibanding variabel independen lainnya. Berdasarkan hasil penelitian dan kesimpulan diatas, ada beberapa saran yang dapat diberikan oleh penulis kepada perusahaan ataupun penulis selanjutnya, yaitu: 1) Bagi Perusahaan diharapkan agar lebih mampu meningkatkan kemapuan dalam memperoleh profitabilitas melalui likuiditas, solvabilitas dan aktivitas. 2) Bagi manajemen perusahaan harus benar-benar memperhatikan tingkat efisiensi dan efektivitas penggunaan modal kerja. 3) Bagi penelitian selanjutnya diharapkan menggunakan variabel lain yang diduga memiliki pengaruh terhadap profitabilitas seperti struktur modal, pertumbuhan penjualan, dan ukuran perusahaan

\section{DAFTAR PUSTAKA}

Ghozali, Imam. 2016. Aplikasi Analisis Multivariate Dengan Program IBM SPSS 23. Semarang: Badan Penerbit Universitas Diponegoro.

Hery, 2015. Analisis Kinerja Manajemen. Jakarta: Grasindo.

Kasmir, 2016. Analisis Laporan Keuangan. Jakarta: Raja Grafindo Persada.

Lestari, Arum Puji Tri. 2017. "Pengaruh Perputaran Kas Perputaran Persedian dan Perputaran Piutang Terhadap Profitabilitas Pada Perusahaan Manufaktur Yang Terdaftar Di BEI Periode 2011-2014. Skripsi, Fakultas Ekonomi. Universitas Negeri Yogjakarta.

Rahmah, Amrita Maulidia dkk. 2016. "Pengaruh Likuiditas, Solvabilitas dan Aktvitas Terhadap Profitabilitas Pada Perusahaan Otomotif Yang Terdaftar Di Bursa Efek Indonesia Periode 2012 - 2014" dalam jurnal Bisma Universitas Pendidikan Ganesha: Volume 4. Skripsi, Universitas Pendidikan Ganesha. Singaraja.

Sugiyono, 2017. Metodo Penelitian Pendidikan. Bandung: Alfabeta.

Supradi, Herman dkk. (2016). "Pengaruh Current Ratio, Debt to Asset Ratio, Total Asset Turn over dan Inflasi terhadap Return On Asset" dalam Jurnal Ilmiah Akuntansi Fakultas Ekonomi: Volume 2 No.2. Universitas Pancasila.

Wulandari,Souvenir Iddha dkk. 2016. "Pengaruh Modal Kerja, Struktur aktiva, Likuiditas, dan Solvabilitas terhadap rentabilitas pada PT Semen Indonesia (Persero) Tbk. (2011-2013)" dalam Jurnal e-Proceeding of Management: Volume 3 No.3. Universitas Telkom. 
Wilona, Brian Muda . 2017. "Pengaruh Tingkat Perputaran Kas Piutang, Perputaran Persediaan Terhadap Profitabilitas Pada Perusahaan Tekstil Yang Terdaftar DI BEI Periode 2012-2016". Fakultas Ekonomi dan Bisnis. Skripsi. Universitas Bhayangkara Surabaya.

Ananto, Erwin E 2015. 2015: Pasar Farmasi Akan Tumbuh 11,8\% jadi US\$4,6 Miliar.

http://indonesia-pharmacommunity.blogspot.com/2015/01/2015-pasar-farmasi-akantumbuh-118-jadi.html?m=0।

Arvianty, Anastasia. 2017. Industri Farmasi Semakin Sehat. Tersedia di m.mediaindonesia.com. Tersedia https://www.google.com/amp/m.mediaindonesia.com/amp/amp_detail/96887industri-farmasi-semakin-sehat

Dahwilani, Dani M. 2017. Peluang dan Tantangan Industri Farmasi di Indonesia 2017. Tersedia di https://www.google.com/amp/s/ekbis.sindonews.com/newsread/1190 701/34/peluang-dan-tantangan-industri-farmasi-di-indonesia-2017-1490187954

Setiawan, Sakina Rakhma Diah. 2018. Proyeksi Pertumbuhan Ekonomi Dunia Redup di 2019 , Ini Sebabnya. https://ekonomi.kompas.com/read/2018/10/22/125746526/proyeksi-pertumbuhanekonomi-dunia-redup-di-2019-ini-sebabnya 